\title{
Ressonância Magnética na Avaliação do Desarranjo Articular Interno da Articulação Temporomandibular
}

\author{
Magnetic Resonance Imaging in the Evaluation of the Internal \\ Articular Derangement of the Temporomandibular Joint
}

\author{
Cristiane Abbehusen ${ }^{1}$ \\ ${ }^{1}$ Centro de Ressonância e Imagem do Hospital Santa Izabel; Salvador, Bahia, Brasil
}

\begin{abstract}
Correspondence addresses: Dra. Cristiane Abbenhusen cristiane.abbehusen@santacasaba. org.br
\end{abstract}

Received: July 22, 2019

Revised: August 27, 2019

Accepted: August 31, 2019

Published: September 27, 2019

Data Availability Statement: All relevant data are within the paper and its Supporting Information files.

Funding: This work was the result of author's initiative. There was no support of research or publication funds.

Competing interests: The author has declared that no conflit of interests exists.

Copyright

(C) 2019 by Santa Casa de Misericórdia da Bahia.

All rights reserved.

ISSN: 2526-5563
O desarranjo articular interno é a principal causa de disfunção da articulação temporomandibular e é definido como uma anormalidade anatômica na relação entre o disco articular e o côndilo da mandíbula. Clinicamente, os principais sintomas são dor, estalidos e limitação da excursão articular. A ressonância magnética é o método de imagem de escolha para a avaliação diagnóstica, pois apresenta excelente resolução de imagem para delimitar o disco articular propriamente dito e a sua relação com as estruturas ósseas adjacentes, inclusive durante estudo dinâmico de abertura da boca. O objetivo deste trabalho é descrever os aspectos de imagem pela ressonância magnética da anatomia normal e do desarranjo articular interno da articulação temporomandibular. Palavras-chave: Articulação Temporomandibular; Desarranjo Articular Interno; Ressonância Magnética.

Internal articular derangement is the main cause of temporomandibular joint dysfunction. It is defined as an anatomical abnormality between the articular disc and the condyle of the mandible. The main clinical symptoms are pain, crackling and limitation of joint excursion. Magnetic resonance imaging is the method of choice for diagnostic evaluation due to the excellent imaging resolution to limit the articular disc and the adjacent bone structures, including during the dynamic mouth opening study. The aim of this paper is to describe the magnetic resonance imaging aspects of normal anatomy and the internal joint disruption of the temporomandibular joint. Keywords: Temporomandibular Joint; Internal Joint Disorder; Magnetic Resonance.

\section{Introdução}

Aressonância magnética (RM) é o padrão ouro de imagem para a avaliação das patologias relacionadas à disfunção da articulação temporomandibular (ATM), pois apresenta uma excelente diferenciação anatômica entres os tecidos fibrocartilaginosos, musculares e ósseos regionais, delimitando facilmente o disco articular, tanto no estudo estático em posição de boca fechada, quanto durante a movimentação dinâmica de abertura bucal.

Várias patologias podem acometer a ATM, incluindo as artropatias inflamatórias e de deposição de microcristais e as doenças infecciosas e neoplásicas. Porém, o desarranjo articular interno é a principal doença que 
acomete esta articulação, sendo descrita em até $28 \%$ da população, ${ }^{1}$ em algum estágio da vida, sendo seus principais sintomas: dor, estalidos e limitação do movimento articular.

O desarranjo articular interno é definido como uma relação anatômica anormal entre o disco articular e o côndilo da mandíbula, estando geralmente relacionada à má oclusão dentária, traumas e alterações da zona bilaminar posterior que contêm estruturas ligamentares de suporte do disco articular.

A RM é considerada o exame de imagem de escolha para o estudo da ATM, pois é o único método de imagem que consegue identificar o disco articular. A tomografia computadorizada, por sua vez, apresenta apenas resolução de imagem para avaliar as estruturas ósseas da articulação, podendo ser utilizada como um método complementar na avaliação de complicações osteoarticulares degenerativas secundárias.

O objetivo deste trabalho é descrever, através da ressonância magnética (RM), a anatomia normal da ATM e as características diagnósticas do desarranjo articular interno.

\section{Anatomia da ATM}

Uma compreensão da anatomia normal e da biomecânica da ATM é essencial para a interpretação precisa dos estudos de imagem.

A ATM é uma articulação sinovial ginglimoartroidal formada pelo côndilo da mandíbula, pela fossa glenoide e pela eminência temporal, cujas corticais ósseas são recobertas por cartilagem. O disco articular é uma estrutura fibrocartilaginosa bicôncava que separa o côndilo da mandíbula das estruturas anatômicas do osso temporal, sendo dividido em bandas anterior e posterior, unido por uma zona intermediária de menor espessura (Figura 1). ${ }^{1} \mathrm{Na} \mathrm{RM}$, o disco articular normal se apresenta com hipossinal homogêneo nas imagens pesadas em densidade de prótons (DP) e T2 (Figura 3).

Normalmente, na posição de boca fechada, o côndilo da mandíbula se posiciona dentro da fossa glenoide ou fossa mandibular e o disco articular encontra-se acima do côndilo, estando à margem posterior da sua banda posterior às " 12 horas", com uma tolerância de $30^{\circ}$ anteriormente (Figuras 2 e 3). E, durante a manobra de

Figura 1. Anatomia da ATM.

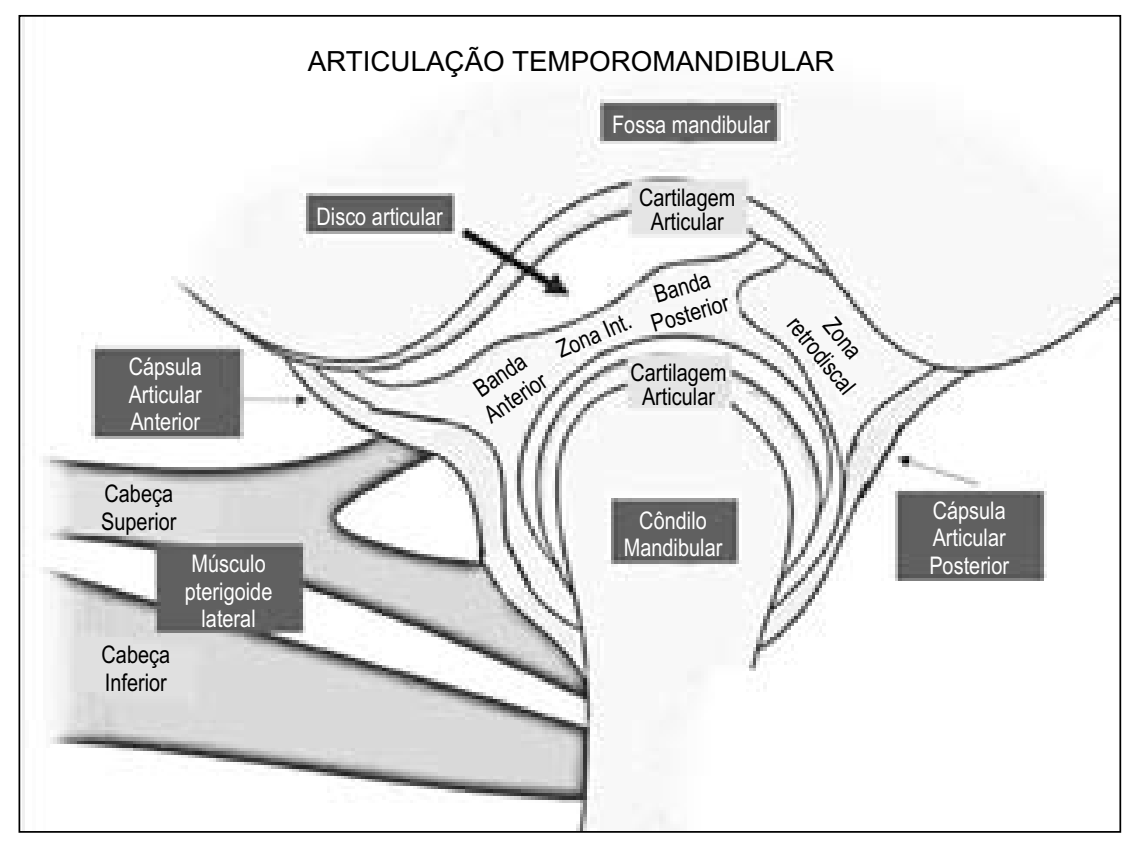


abertura da boca, enquanto o côndilo se desloca anteriormente, saindo da fossa glenoide e se posicionando abaixo da eminência temporal, o disco deve permanecer acima do côndilo, evitando o atrito entre as superfícies ósseas da articulação (Figura 4).

Figura 2.Posição normal do disco articular na posição de boca fechada, entre $0^{\circ}$ e $30^{\circ}$.

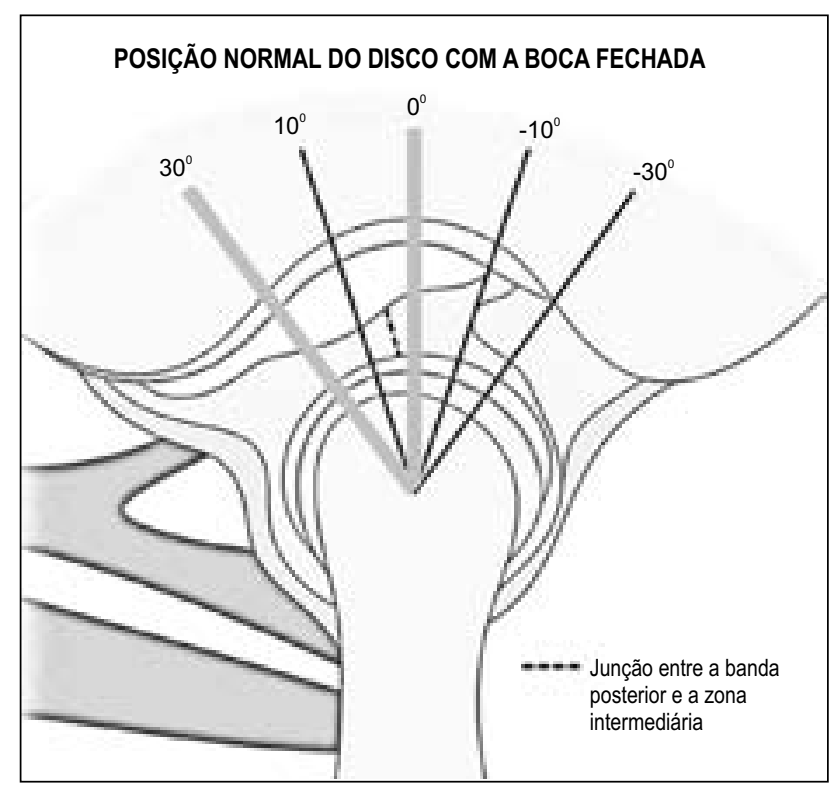

A estabilidade do disco acima do côndilo durante o amplo movimento desta articulação é possibilitada pela presença de um tecido retrodiscal de suporte, composto de gordura, feixes vásculonervosos e uma zona bilaminar fibrocartilaginosa, com bandas ou ligamentos superior e inferior, que se fixam à cápsula articular e ao osso temporal (Figura 3).

O músculo pterigoide lateral também é uma estrutura anatômica regional importante, estando inserido na margem anterior do côndilo da mandíbula, sendo responsável pela execução do movimento de abertura da boca (Figura 3).

\section{Desarranjo Articular Interno}

A ATMé uma das articulações mais ativamente utilizadas do corpohumano.Até $28 \%$ da população apresenta sintomas relacionados à disfunção da ATM e aproximadamente 7\% procuram tratamento. ${ }^{1-3}$ A maior prevalência é no sexo feminino, que corresponde a aproximadamente $80 \%$ dos pacientes em tratamento de distúrbios da ATM, sobretudo entre 20 e 40 anos de idade. Os sintomas do desarranjo articular interno incluem dor localizada e crepitações durante a abertura da boca, bem como limitação do movimento articular, que pode ser exacerbada na presença de artrose secundária da articulação. O diagnóstico clínico da ATM é um desafio, particularmente considerando os fatores psicossociais e hormonais que podem estar envolvidos nos distúrbios da dor.

O desarranjo articular interno é caracterizado pelo deslocamento anterior do disco articular na posição de boca fechada (Figura 5), com ou sem reposicionamento anatômico durante a manobra de abertura da boca. Para este diagnóstico através da RM, são realizadas imagens sagitais DP nas fases de boca fechada e de abertura máxima da boca, colocando-se um espaçador bucal (Figuras 4 a 6$)$.

$\mathrm{Na} \mathrm{RM}$, o deslocamento discalanormal é dividido classicamente em dois tipos: (1) deslocamento anteriornaposição de boca fechada, voltando a se posicionar acima do côndilo durante a manobra de abertura da boca (Figura 4) e, (2) deslocamento anterior do disco tanto na posição de boca fechada quanto durante a abertura bucal, também conhecido como deslocamento anterior sem recaptura discal (Figura 5).

$\mathrm{Na}$ abertura bucal, (Figura 6), o disco permanece anteriorizado.

Classicamente, o deslocamento discal é classificado em dois tipos: (I) deslocamento anterior na posição de boca fechada, voltando a se posicionar acima do côndilo da mandíbula durante a abertura bucal e, (II) deslocamento anterior tanto na posição de boca fechada quanto na posição de boca aberta, ou seja, o disco permanece fixo anteriormente, também conhecido como deslocamento anterior, sem recaptura discal. Neste segundo tipo, que representa o grau mais severo do desarranjo articular interno, é comum se observar alterações degenerativas no disco, como focos internos de 
Figura 3. RM plano sagital boca fechada DP, anatomia normal: côndilo mandibular dentro da fossa glenoide e disco articular acima do côndilo. 1: côndilo da mandíbula, 2: disco articular, 3: fossa glenoide, 4: eminência temporal, 5:músculo pterigoide lateral, 6 : tecido retrodiscal, 7 : conduto auditivo externo; 8:mastoide.

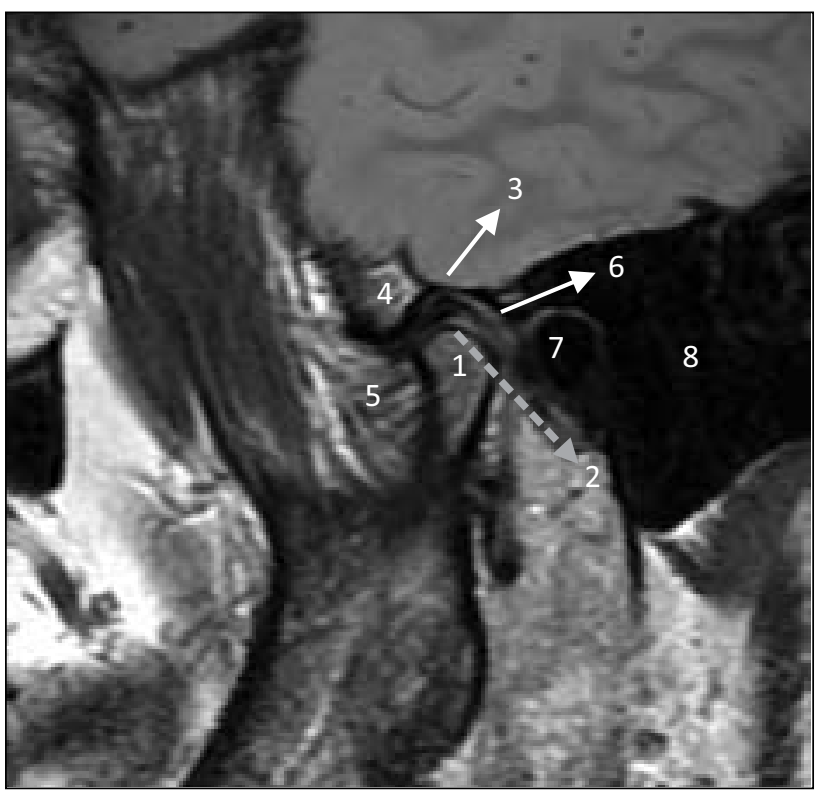

Figura 4. RM plano sagital boca aberta DP, anatomia normal: o côndilo da mandíbula sai da fossa glenoide (3) e se posiciona abaixo da eminência temporal (4), enquanto o disco (2) acompanha o movimento, permanecendo acima do côndilo mandibular (1).

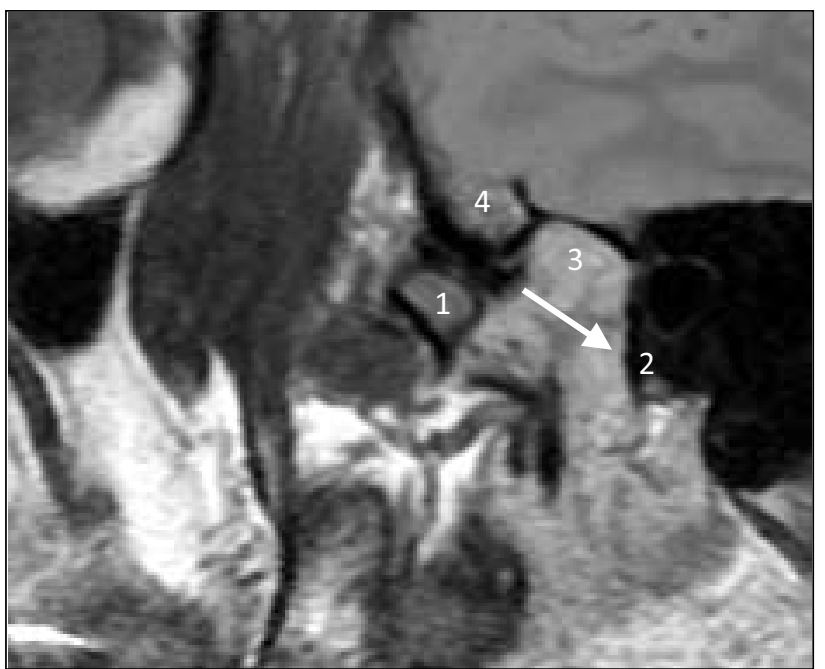

Figura 5. RM plano sagital boca fechada, disco articular deslocado anteriormente, à frente do côndilo da mandíbula. 1: côndilo da mandíbula, 2: disco articular, 3: fossa glenoide.

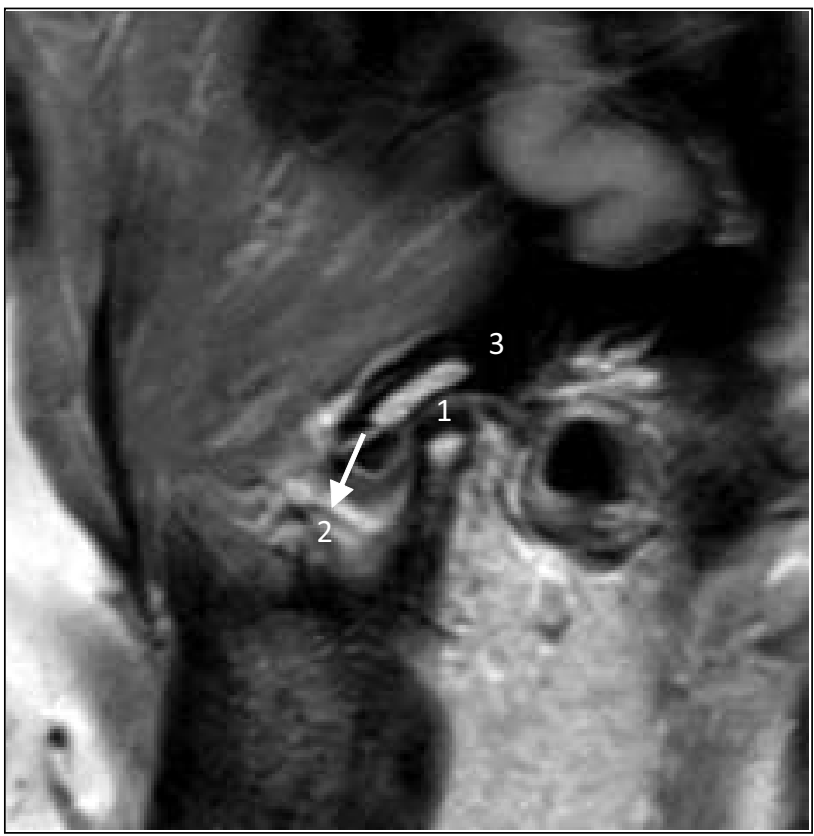

Figura 6. RM plano sagital boca fechada, o disco articular está anteriorizado à frente do côndilo da mandíbula. Disco bastante degenerado, com focos de hipersinal na banda posterior e com contornos irregulares.

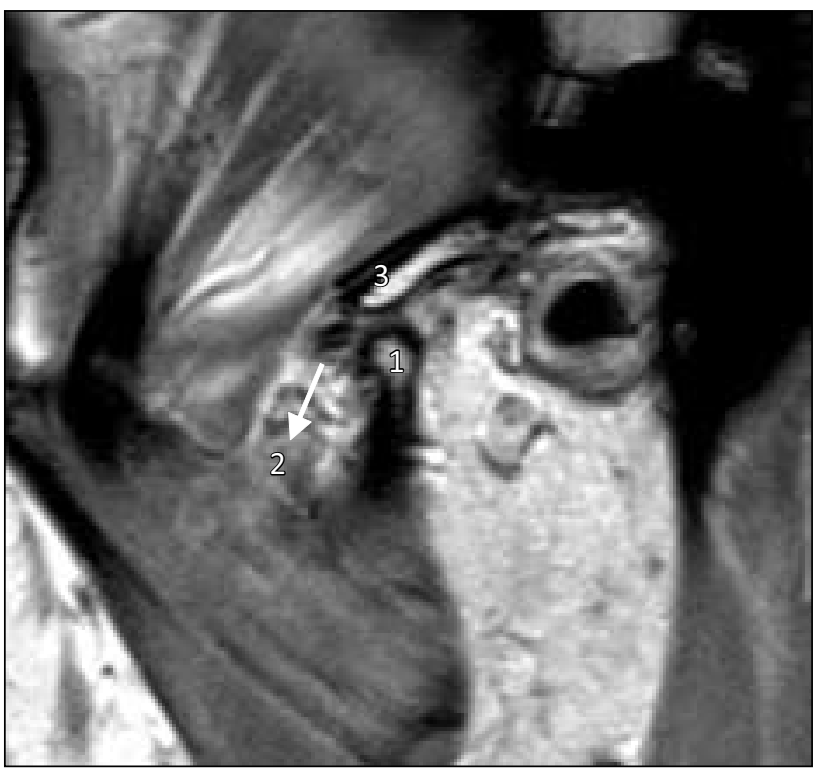


elevado sinal, irregularidade de contornos e redução das suas dimensões (Figuras 5 e 6), bem como sinais de rotura de ligamentos da banda posterior (Figura 6).

O principal sintoma clínico do deslocamento do tipo II é a crepitação durante o movimento articular. Por outro lado, o tipo I pode ser encontrado até em indivíduos assintomáticos. Larhein e colaboradores, ${ }^{2}$ avaliando pacientes e voluntários assintomáticos, observaram um discreto deslocamento anterior do disco articular na posição de boca fechada em até $22,6 \%$ dos voluntários assintomáticos do seu estudo, todos demonstrando reposicionamento discal na manobra de abertura da boca. O tipo II só foi descrito em pacientes com queixas clínicas.

$\mathrm{O}$ disco articular pode ainda apresentar deslocamentos lateral ou medial, associados ou não ao deslocamento discal anterior. Esse diagnóstico é realizado através de imagens no plano coronal da RM. O disco normalmente recobre homogeneamente, de um lado a outro, a superfície superior do côndilo da mandíbula. As imagens coronais DP possibilitam ainda avaliar a morfologia do côndilo da mandíbula e identificar alterações ósseas degenerativas secundárias no côndilo e na cavidade glenoide, caracterizadas por retificação da convexidade condilar superior usual, esclerose óssea subcortical, cistos e erosões nas superfícies articulares, redução da amplitude do espaço articular (Figura 7) e, em estágios mais avançados, a anquilose ou fusão das margens da articulação.

O derrame articular também pode ser visualizado facilmente nas imagens sagitais com ponderação T2 e supressão de gordura, e está mais comumente relacionado ao sintoma de dor local na articulação (Figura 8). ${ }^{3}$

E, por fim, os estudos dinâmicos realizados em cine, também são utilizados nos protocolos de estudo da ATM pela RM e são importantes para avaliar, em tempo real, a amplitude do movimento do côndilo e do disco articular, e ainda diagnosticar subluxação ou luxação da articulação.
O tratamento do desarranjo articular interno da ATM é multidisciplinar e inclui fisioterapeutas, psicólogos, odontologistas e otorrinolaringologistas, podendo ser utilizados

Figura 7. RM plano coronal boca fechada, alterações degenerativas no côndilo da mandíbula com retificação da margem superior, erosões corticais $\left(^{*}\right)$ e redução do espaço articular.

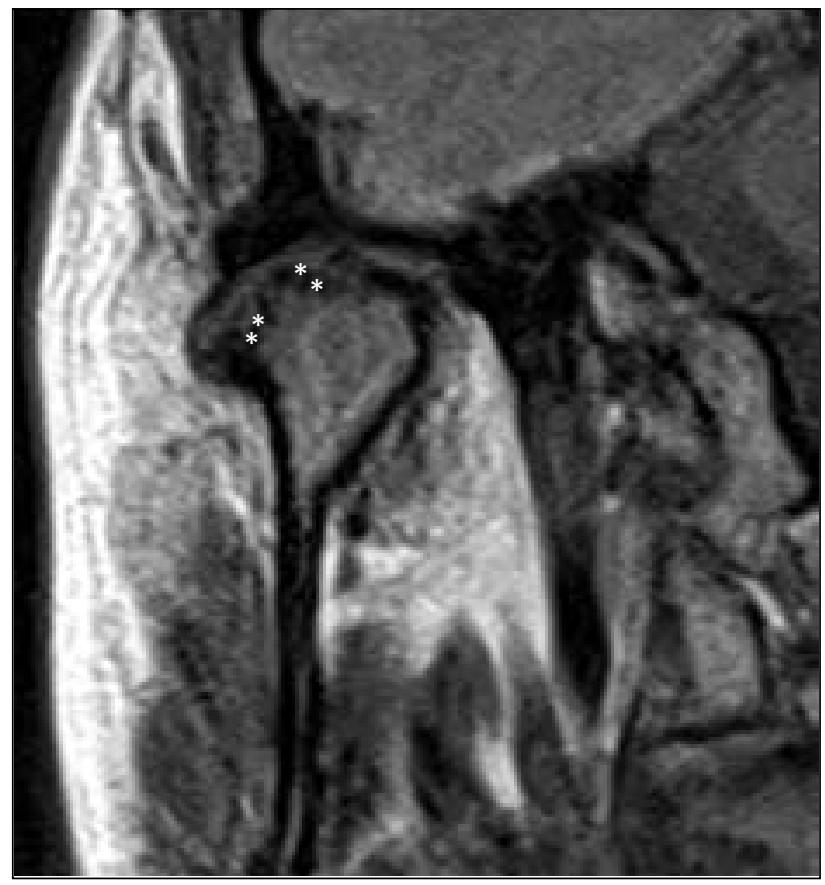

Figura 8. RM plano sagital boca fechada, derrame articular visto como líquido com sinal elevado nesta técnica T2 com supressão de gordura.

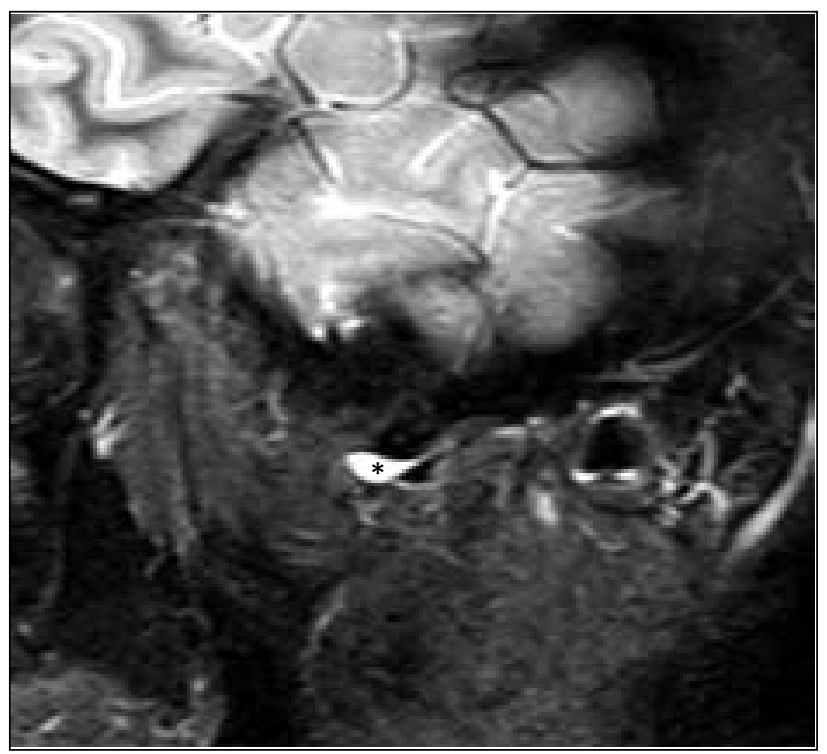


analgésicos, fisioterapia, drogas para relaxamento muscular, como toxina botulínica e ainda placas odontológicas. ${ }^{4} \mathrm{Em}$ caso de falência destas opções terapêuticas, injeções intra-articulares de corticoide e cirurgia podem ser necessárias. $\mathrm{O}$ diagnóstico precoce colabora com uma melhor resposta terapêutica e pode prevenir artrose secundária da ATM.

\section{Conclusão}

O desarranjo articular interno é uma causa importante de disfunção da ATM, mais comumente descrita no sexo feminino e de avaliação e tratamento multidisciplinar. $\mathrm{O}$ diagnóstico é realizado através da RM, uma vez que é o único método de imagem que identifica o disco articular, tanto em posição de boca fechada quanto durante a manobra de abertura bucal.

\section{Referências}

1. Petscavage JM, Walker TRA. Unlocking the jaw: Advanced imaging of the temporomandibular joint. AJR:203. November 2014:1047-58.

2. LarheimTA, Westesson PL, SanoT, Temporomandibular joint disk displacement: Comparison in asymptomatic volunteers and patients. Radiology. 2001;218:428-32.

3. Tomas X, Pomes J, Berenguer J, Quinto L, Nicolau C, Mercader JM, Castro V, MDMR Imaging of temporomandibular joint dysfunction: A pictorial review. RadioGraphics 2006; 26:765-781.

4. Calderon PS, Reis KR, Araujo CRP, Rubo JH, Conti PCR. Ressonância magnética nos desarranjos internos da ATM: sensibilidade e especificidade. Rev DentPress Ortodon Ortop Facial. 2008;13:2. 